\title{
Bencana Tsunami dan Upaya Penanggulangannya
}

\author{
Oleh : Bambang Suhendro
}

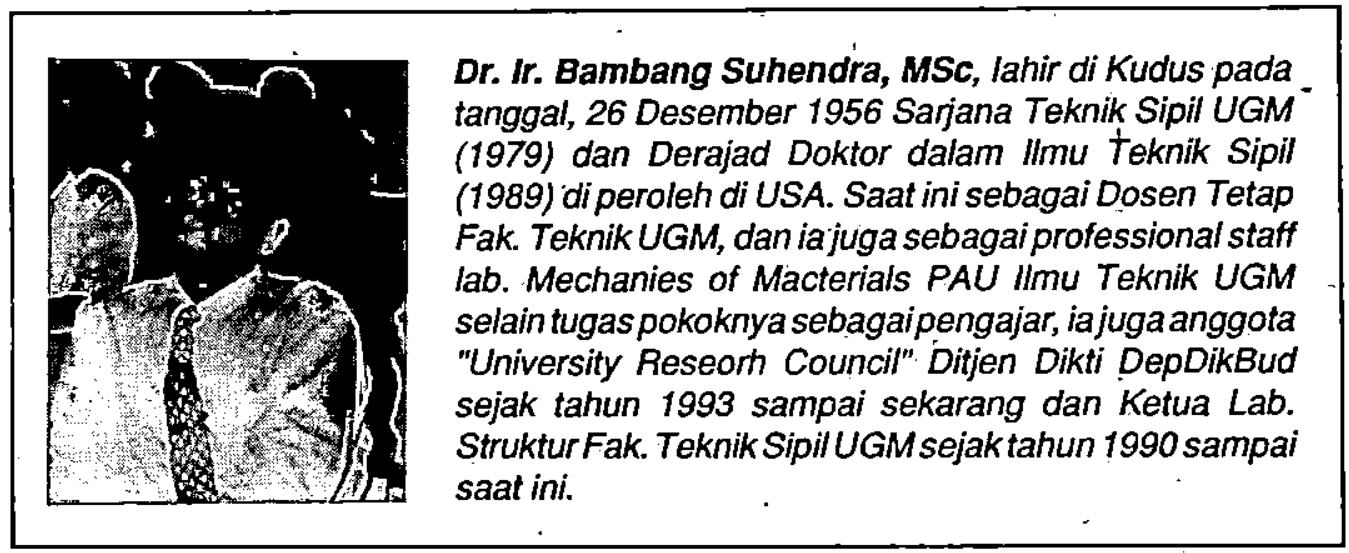

\section{Pendahuluan}

Indonesia, yang memiliki pantai terpanjang di dunia dan terletak di daerah berkerak-bumi yang labil, mempunyai potensi besar terhadap kemungkinan terjadinya tsunami.Potensi tersebutmenjadi lebih besarlagi karena sebagian besar pusat gempa-bumi tektonik, yang menjadi penyebabutamaterjadinyatsunami, terletak di dasar lautan dan sambung-menyambung sepanjang pantai mulai dari pantai barat Sumatera, pantai selatan Jawa, pantai di pulau-pulau Nusa-Tenggara, Maluku, sampai Sulawesi Utara (Gambar 1).

Sejak tahun 1900 sudah tercatat setidaknya sebanyak sepuluh kali tsunami. yang terjadi di pantai-pantai Indonesia, atau rata-rata satu kejadian setiap. sembilan tahun. Tenggang waktu antara tsunami yang terjadi di Banyuwangi pada bulan Juni 1994 yang baru lalu, yang memporak porandakan beberapa desa nelayan dan menelan korban lebih dari 200 orang, dengan tsunami sebelumnya yang terjadi di Halmahera pada bulan Januari 1994 dan Kabupaten SikkaFlorespadabulan Desember 1992,memang sangat singkat. Ketiga tsunami tersebut disebabkan oleh gempa tektonik dasar laut berkekuatan sekitar 6,8 skala Richter. Peta tsunami yang pernah terjadi di.Indonesia sejak tahun 416 sampai dengan tahun 1992 disajikan pada Gambar 2 (Sudrajat, 1994).

Tsunami yang terjadi di pantai Pulau

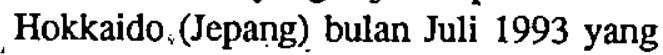
baru lalu, yang tinggi gelombangnya mencapai lebih dari 10 meter dan terjadi di tengah malam serta menewaskan lebih dari 100 orang, menghancurkan lebih dari 100 rumah, dan menenggelamkan lebih dari 200 kapal, disebabkan pula oleh gempa tektonik di dasar laut berintensitas 7,8 pada skala Richter (Makuhara, 1993). Peristiwa 
serupa terjadi pada tahun 1983 di tempat yang sama dan menewaskan 106 orang. Tsunami terburuk yang terjadi di Jepang pada tahun 1896-dengantinggi gelombang yang menerjang pantai mencapai 30 meter - sempat menewaskan 27.000 orang dan menghancurkan lebih dari 10.000 rumah (Newmar \& Rosenblueth, 1971).

- Menyadari dahsyatnya bencana yang diakibatkan oleh tsunami, dan potensi kemungkinan terjadinya tsunami di pantaipantai Indonesia cukup besar maka penanggulangan bencana tsunami sudah mendesak untuk diupayakan. Beberapa pemikiranupaya penanggulangan disajikan dalam paper ini.

\section{Mekanisme Tsunami}

Tsunami, yang dalam bahasa Jepang berarti "gelombang pásang di pelabuhan", dapat ditimbulkan oleh : (a) tectonic displacement atau pergeseran vertikal kerak bumi di dasar laut dalam yang berkaitan dengan gempa bumi tektonik lepas pantai, (b) longsoran raksasa dari batuan tebing di dasar laut yang dipicu oleh gempa bumi, seperti yang terjadi di teluk Sagami-Jepang pada tahun 1933, atau (c) letusan gunung berapi di laut, seperti gunung Krakatau pada tahun 1883, yang menewaskan 36.000 orang (Wiegel, 1970 : Newmark \& Rosenblueth, 1971; Dowrick, 1987). Menurut Hendrajaya (1993), aktivitas gempa tekțonik mampu mempengaruhi aktivitas erupsi gunung berapi di jalur vulkanik daerah subduksi.

- Sebagian besar tsunami yang terjadi di dunia disebabkanroleh pergeseran vertikal kerak bumi di dasar laut dalam yang berkaitan dengan gempa bumi tektonik lepas pantai (Gambar 3). Perubahan dasar laut secara mendadak tersebut diikuti oleh perubahan tempat massa air laut secara mendadak pula, yang dapat menimbulkan gelombang air laut yang sangat panjang (dapat mencapai $800 \mathrm{~km}$ ) dengan periode gelombang yang lama (dapat mencapai 60 menit). Gelombang tersebut menjalar dengan kecepatan yang sangat tinggi (dapat mencapai $800 \mathrm{~km}$ per jam) secara frontal dengan arah tegak lurus terhadap bidang pergeseran dasar laut, yang biasanya terjadi pada zona subduksi.

Setelah mengalami refraksi, defraksi, ataupun pendangkalan (shoaling), gelombang tsunami yang mencapai pantai dapat berubah menjadi gelombang pasang yang sangat tinggi sampai beberapa puluh meter di atas elevasi air pasang normal tertinggi. Elevasi muka air laut tertinggi yang dapat dicapai oleh tsunami yang running up ke pantai dikenal sebagai runup elevation, sedangkan elevasi terendah dikenal sebagai drawdown elevation (Gambar 4).

Gempa-gempa yang terjadi di lepas pantai banyak pula yang tidakmenimbulkan tsunami, karena magnitude-nya yang kecil atau pusat gempanya yang cukup dalam. Menurut Iida (1963), berdasarkan studi tsunami yang terjadi di Jepang sejak 1900 sampai dengan 1960, hubungan antara magnitude gempa, kedalamản pusatgempa, dan terjadinya tsunami dapat disajikan dalam suatu grafik yang dilukiskan pada Gambar 5.

\section{Karakteristik Gelombang Tsunami}

Sesuai mekanisme yang telah diuraikan sebelumnya, gelombang tsunami memiliki karakteristik : (a) panjang gelombang, L, yang amat besar, (b) periode 
gelombang, $T$, yang lama, (c) kecepatan penjalaran, V, yang tinggi, dan (d) rasio antara panjang gelombang dengan kedalaman dasar laut, $\mathrm{L} / \mathrm{D}$, yang lazimnya melebihi 20. Teori matematik gelombang tsunami cukup rumit karena $\mathrm{V}$ amat tergantung dari $\mathrm{L}$ dan $\mathrm{D}$.

Beberapa fenomena gelombang tsunami yang dapat diamati dari pengalaman masa lalu (Dowrick, 1987) adalah sebagai berikut ini.

(a) Semakinbesarmagnitudegempa(M) dan semakin besar kedalaman laut (D) dimana tectonic displacement dasar laut terjadi, maka energi tsunami (E) akan semakin besar, panjang gelombang (L) semakin besar, dan periode gelombang $(T)$ akan semakin panjang.

(b) Semakin besar kedalaman laut (D) maka akan semakin besar pula kecepatan penjalaran gelombang $(V)$ menuju pantai. Formula yang dapat dipakai untuk mempèrkirakan kecepatan penjalaran gelombang tsunami adalah $: \mathrm{V}=\sqrt{\mathrm{g} D}$, dengań $\mathrm{g}=$ percepatan grafitasi.

\section{Potensi Tsunami di Indonesia}

Di sepanjang pantai barat Sumatera dan pantai selatan Jawa zona subduksi dimana gempa tektonik lepas pantai bersarang- hampir sejajar dengan garis pantai. Mengingat gelombang tersebut menjalar secara frontal dengan arah tegak lurus terhadap bidang. subduksi maka apabila topografi dasarlaut dan garis pantai diketahui, secara garis besar trayek penjalaran tsunami ke pantai dapat diperkirakan.

Teluk-teluk, yang merupakan ladang subur untuk mencari ikan, maupun pelabuhan-pelabuhan, yang padaumumnya dibangun di ketiak-ketiak suatu teluk atau di dekat muara sungai, merupakan tempat yang paling potensial terjadi tsunami, karena di tempat-tempat itu topografi garis pantai cenderung menyempit sehingga mengakibatkan terakumulasi dan terkonsentrasinya energi gelombang tsunami.

Pelabuhan-pelabuhan nelayan biasanya juga memiliki pantai yang ländai sehingga memungkinkan tsunami untuk merayap naik ke daratan, yang pada umumnya dipakai sebagai perkampungan nelayan.

\section{Berbagai Tipe Kerusakan yang} Ditimbulkan oleh Tsunami

, Kerusakan yang ditimbulkan oleh gelombang tsunami amatberagam dan dapat dikelompokkan menjadi beberapa tipe sebagai berikut : (a) kerusakan struktural bangunan akibat gaya hidrodinamik gelombang, (b) keruntuhan struktur bangunan karena fondasinya tergerus arus air laut yang amat deras, (c) kerusakan struktural bangunan akibathantaman bendabenda keras, seperti kapal dan semacamnya, yang terbawa oleh gelombang.

Upaya Penanggulangan Bencana Tsunami

Mengingat tsunami menjalar secara frontal dengan arah tegak lurus terhadap bidang subduksi, sedangkan secara garis besar zona subduksi di Indonesia telah diketahui posisinya, maka secara garis besar pula teluk-teluk dan pelabuhan-pelabuhan yang potensial terhadap bahaya tsunami (yaitu yang menghadap langsung ke zona subduksi) dapat tetapkan, dan trayek penjalaran tsunami ke teluk-teluk atau pelabuhan-pelabuhan, tersebut dapat 
diperkirakan.

Berdasarkan pemahaman atas mekanisme terjadinya tsunami, karakteristik gelombang tsunami, inventarisasi dan identifikasi kerusakan struktur bangunan akibat tsunami, dan beberapa pengalaman berharga yang diperoleh dari bencana tsunami di masa lalu, beberapa alternatif upaya penanggulanggan bencana tsunami yang dapat ditempuh adalah sebagai berikut ini.

Penataan kembali (relocation) lahan pantai. Pada tempat-tempat yang potensial terjadi tsunami, penataankembali lahanpantai harus dilakukan. Pembangunan pemukiman yang terletak terlalu dekat dengan garispantai harus dihindari. Daerah di sepanjang garis pantai setebal 200 meter perlu dihijaukan kembali dengan hutan mangrove dan pohon-pohon besar lainnya seperti pohon kelapa yang berlapis-lapis. Batu-batu karang perlu dibiarkan tumbuh karena dapat berfungsi sebagai pemecah gelombang alami.

Melestar̈ikan hutan Mangrove. Hutan mangiove, yang secara alami hanya dijumpai di pantai-pantai daerah tropik, pada umumnya terbentuk oleh pepohonan halofit - yaitu pohon-pohon yang dapat bertahan hidup pada kondisi tanah yang tergenang terus menerus dengan tingkat salinitas (kadargaram) yang tinggi - seperti pohon bakau (Rhizophora mucronata), pohon tanjang (Bruguiera cylindrica), dan pohon nipah. Hutan mangrove mempunyai tajuk yang rata dan rapat, memiliki sistem perakaran yang kuat dan istimewa, dan selalu berdaun lebat sepanjang waktu (Munir, 1992). Hutan mangrove dapat mencapai ketebalan sampai 200 meter di garis pantai dan ketinggian pohon sampai
30 meter. Déngan kondisi seperti itu hutan mangrove dapat berfungsi ideal sebagai perisai alami pelindung pantai dari ancaman gelombang tsunami, angin kencang, maupun erosi. Ironisnya daerah pantai yang telah dimanfaatkan oleh manusiasebagai pelabuhan, perkampungan nelayan, zona industri, maupun obyek pariwisata, hutan mangrove tersebut justru dimusnahkan.

Pembuatan pemecah gelombang atau overtopping seawall. Salah satu metode untuk melindungi suatu daerah di tepi pantai dari gelombang tsunami adalah dengan membuat pemecah gelombang (break water) di laut, seperti terlihat pada Gambar 6-a, atau overtopping seawall di darat, seperti pada Gambar 6-b (Newmark \&Rosenblueth, 1971; Wiegel, 1970). Kedua strukturtersebutharuscukupkuat dan stabil untuk menahan gaya hidrodinamik gelombangdan gaya-gaya lain yang timbul. Cara ini memang cukup mahal namun pada kondisi tertentu cukup efektif untuk mengurangi atau bahkan mencegah bencana yang diakibatkan oleh gelombang tsunami.

Membuat struktur tahan tsunami. Analisis secara rinci terhadap kerusakan struktural bangunan akibat gelombang tsunami dapat memberikan gambaran perkiraan mengenai besardan karakteristik gaya hidrodinamik yang ditimbulkan oleh suatu tsunami. Informasi ini amat diperlukan untuk mengembangkan pedoman perancangan sistem strukturtahan tsunami. Beberapa pedoman praktis yang dapat dipakai adalah : (a) sisi yang panjang dari struktur bangunan sedapat mungkin diarahkan sejajar dengan antisipasi arah penjalaran gelombang tsunami agar kekuatan lateral struktur pada arah tersebut. 
relatif lebih besar, sementara gaya akibat tekanan air yang bekerja relatif lebih kecil; (b) shear wall atau lateral bracing ditempatkan searah dengan penjalaran gelombang tsunami; .(c) lantai terbawäh dari bangunan bertingkat sebaiknya dibuat terbuka sama sekali, atau dindingnya terbuat 'dari bahan yang mudah retak, agar gelombang tsunami dapat lewat dengan leluasa sehingga mengurangi beban horisontal pada struktur, sementara lantailantai di atasnya digunakan untuk mengungsi; (d) fondasi menerus terbukti memiliki ketahanan (resistance) yang jauh lebih baik untuk menahan gerusan akibat arus airyang deraspada saatterjadi tsunami; (e) sistem struktur juga harus tahan gempa, karena boleh jadi bangunan tersebut akan terlanda gempa terlebih dahulu sebelum gelombang tsunami menyusul datan; (f) struktur juga diperhitungkan terhadap benturan benda keras akibat kapal. atau benda lain yang terlempar pada saat gelombang pasang menyerbu pantai.

Waming system. Sistem peringatan (waming system) pada kondisi dan batasbatas tertentu merupakan cara yang ekonomis untuk mitigasi ataupunmencegah korban jiwa yang diakibatkan oleh tsunami (korban harta benda berupa porak porandanya bangunan dan segala isinya tidak dipedulikan). Sebagai contoh, gempa bumi lepas pantai yang terjadi di Chili beberapa tahun yang lalu, dapat diketahui lebih dulu bahwa gelombang tsunami akan menjalar ke Hawaii dan Jepang. Karena jaraknya yang cukup jauh (meskipun kecepatannya mencapai $800 \mathrm{~km} / \mathrm{jam}$ ), tsunami baru akantiba dikedua tempattersebut sekitar 10 dan 20 jam kemudian, maka peringatan untuk mengungsi dapat diberikan dan pemerintah setempat maupun pendudúk mempunyai cukup waktu untuk melakukannya. Apabila pusat gempa bumi lepas pantai berjarak hanya beberapa ratus kilometer dari pantai, seperti kondisi di Indonesia, sehingga waktu tempuhnya hanya beberapa puluh menit, sistem waming memang tidak efektif. Meskipun demikian, penyuluhan kepada para warga yang bermukim di perkampungan nelayan dan para pejabat setempat tentang tanda-tanda nyata akan terjadi tsunami, yaitu surutnya secara mendadak dan drastis elevasi muka airlaut yangdipantai-pantailandai ditandai dengan majunya genangan air laut șampai ratusan meter ke arah laut (Gambar 4), amat perlu untuk dilakukan. Bila tandatanda tersebut terjadi, para nelayan harus segera mengungsi/menjauh beberapa ratus meter dari pantai karena beberapa puluh menitlagi gelombang pasang tsunami dapat dipastikan akan datang menerjang pantai tersebut. Ironisnya, seperti yang terjadi di pantai selatan pulau Bali tahun 1977 yang lalu, karena ketidak-tahuannya, sebagian besar warga perkampungan nelayan di pantai tersebut malah beramai-ramai menuju laut yang surut untuk memunguti ikan yang menggelepar, padahal sekitar dua puluh menit kemudian gelombang pasang tsunami datang menyerbu pantai dan menyapu bersih beberapa desa beserta penghuninya dan menelan korban ratusan orang.

\section{Kesimpulan}

Sebagian besar pusat gempa-bumi tektonik di Indonesia terletak didasarlautan dan menjadi penyebab utama terjadinya tsunami. Teluk-teluk, pelabuhanpelabuhan, dan muara-muara sungai di 
sepanjang pantai barat Sumatera, pantai selatan Jawa, pantai di pulau-pulau Nusa Tenggara; Maluku, sampai Sulawesi Utara, perlu diwaspadai terhadapbencanatsunami, dan diupayakan metode penanggulangannya.

Beberapa fenomena gelombang tsunami yang dapat diamati dari pengalaman masa lalu adalah : (a) semakin besar magnitude gempa dan semakin besar kedalaman laut dimana tectonic displacementdasarlaut terjadi, makaenergi tsunami akan semakin besar, panjang gelombang semakinbesar, danperiodegelombangakan semakin panjang :. (b) semakin besar kedalaman laut maka semakin besar pula kecepatan penjalaran gelombang menuju pantai.

Upaya yang dapat ditempuh untuk penanggulangan bencana tsunami adalah: (a) penataan kembali lahan pantai, (b) pelestarian hutan mangrove,(c) pembuatan struktur pemecah 'gelombang atau overtopping seawall,(d) membuat struktur tahan tsunami, dan (e) warning system.

\section{Daftar Pustaka}

Cox, A., Hart, R.B., 1986, Plate Tectonics -How It Works, Black well Scientific Publications, Califomia.
Dowrick, D.J., 1987, Earthquake Resistant Design ForEngineers and Architects - 2nd ed., John Wiley \& Sons, New York.

Hadi, S., 1993,' Pemodelan Ev́olusi Pantai Akibat Pengaruh Gelombang dan Arus Laut - Studi Kasus Pantai Anyer, Carita, Jawa Barat, Laporan Kemajuan Penelitian Hibah Bersaing DIKTI.

Hendrajaya, L., 1993, Keterpengaruhan Aktivitas Erupsi Gunung Api Oleh Aktivitas Gempa Tektonik di Busur VulkanikDaerah Subduksi,Laporan Kemajuan Penelitian Hibah Bersaing DIKTI.

Kramadibrata, S., 1985, Perencanaan Pelabuhan, GaneçaExact, Bandung. Makihara, K., July 1993, Tsunami Horror, Time Inc., New York.

Newmark, N.M., Rosenblueth, E., 1971, Fundamentals of Earthquake Engineering, Prentice Hall-Inc., New Jersey.

Munir, M., Desember 1992, Hutan Mangrove -. Jalur Hijau Penyelamat Pantai, Asri, Yayasan Eksotika Enterprise, Jakarta.

Sudradjat, A.,Juni 1994, Sekali lagi Tentang Tsunami, PT. Kompas Media Nusantara, Jakarta.

Wiegel, R.L., 1970, Eartquake Engineering; Prentice Hall-Inc., New Jersey. 


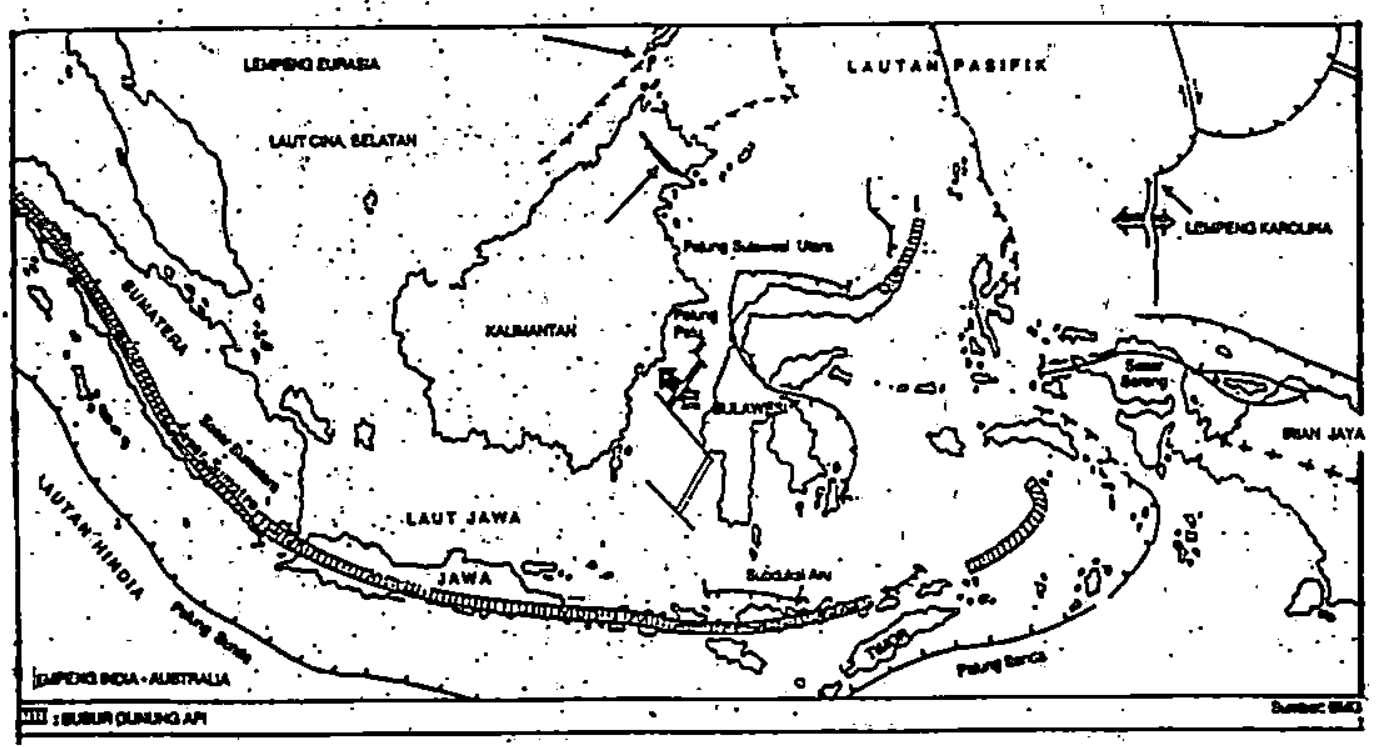

Oambar 1 : Peta tektonik Indonesia

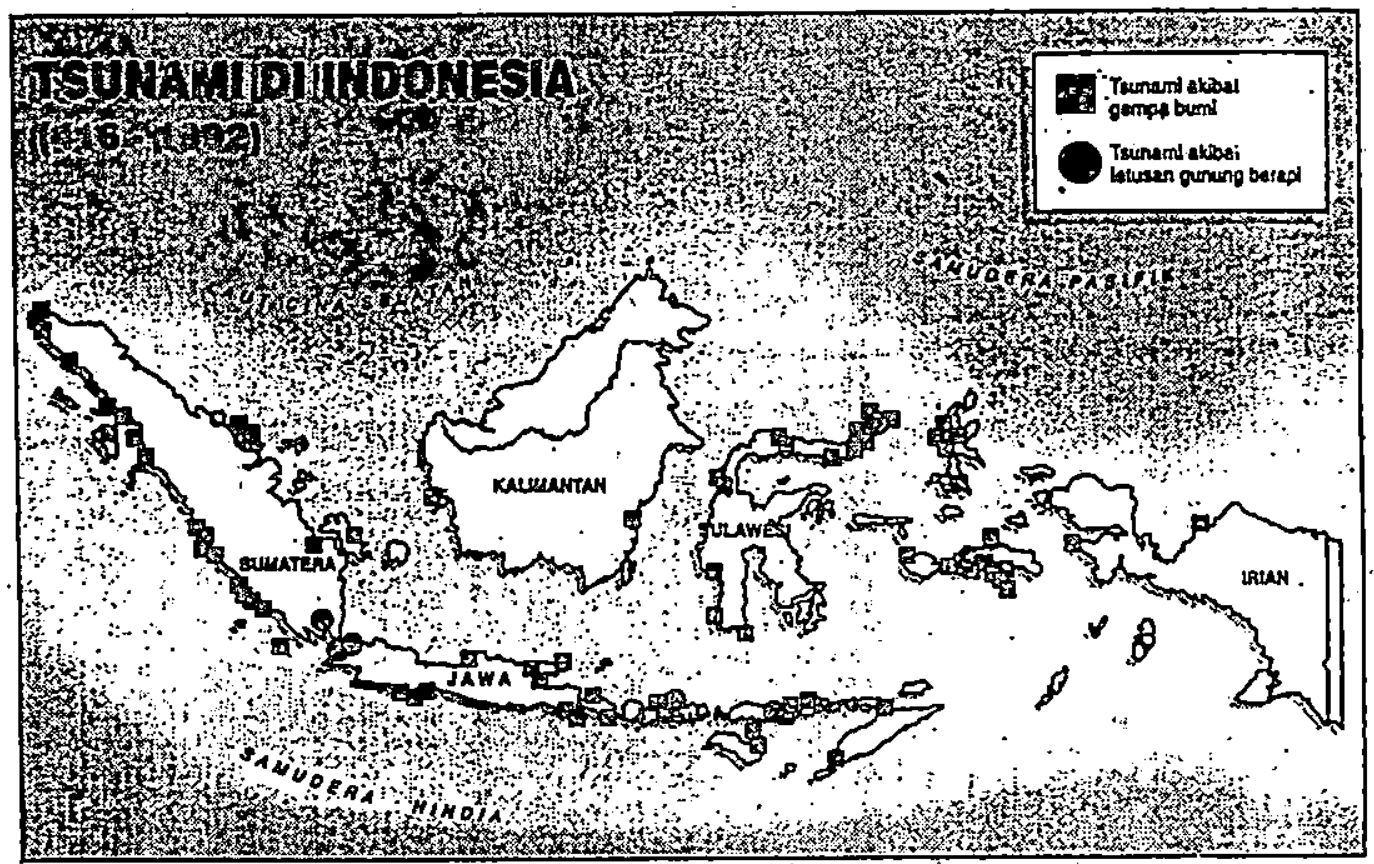

Gambar 2 : Peta tsunami Indonesia 


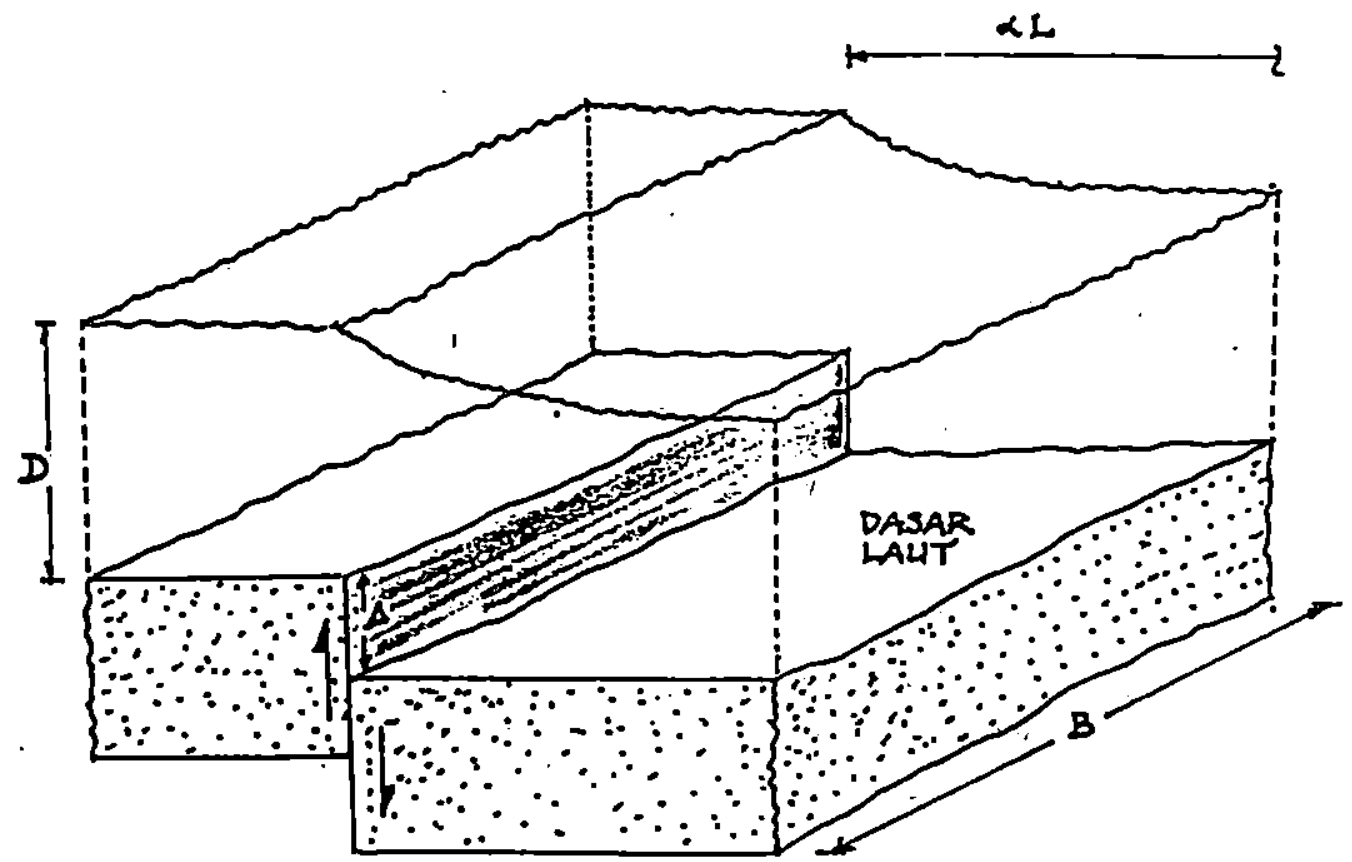

Gambar 3 : Vertical tectonic displacement

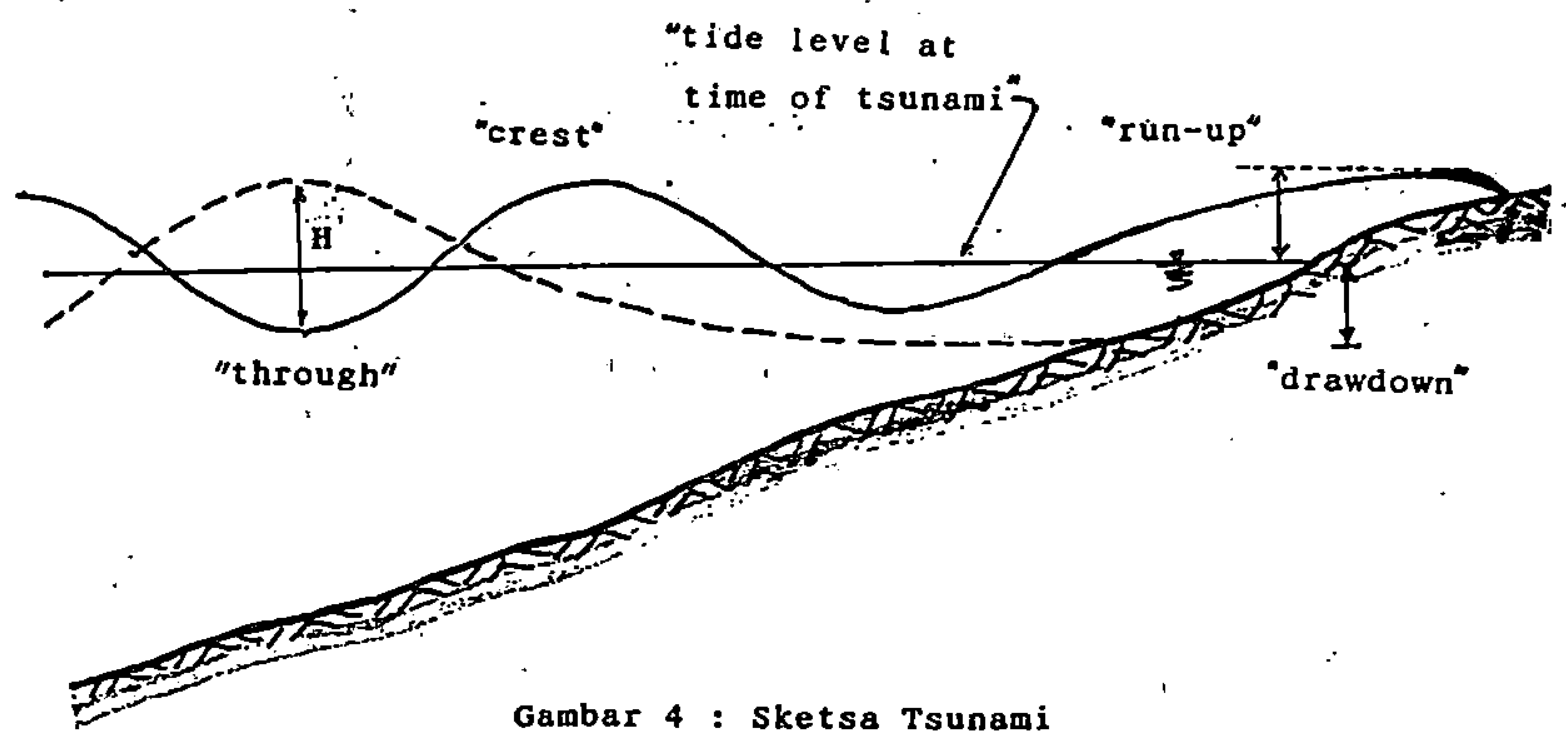


Bambang Suhendro, Bencana Tsunami dan Upaya Penanggulangannya

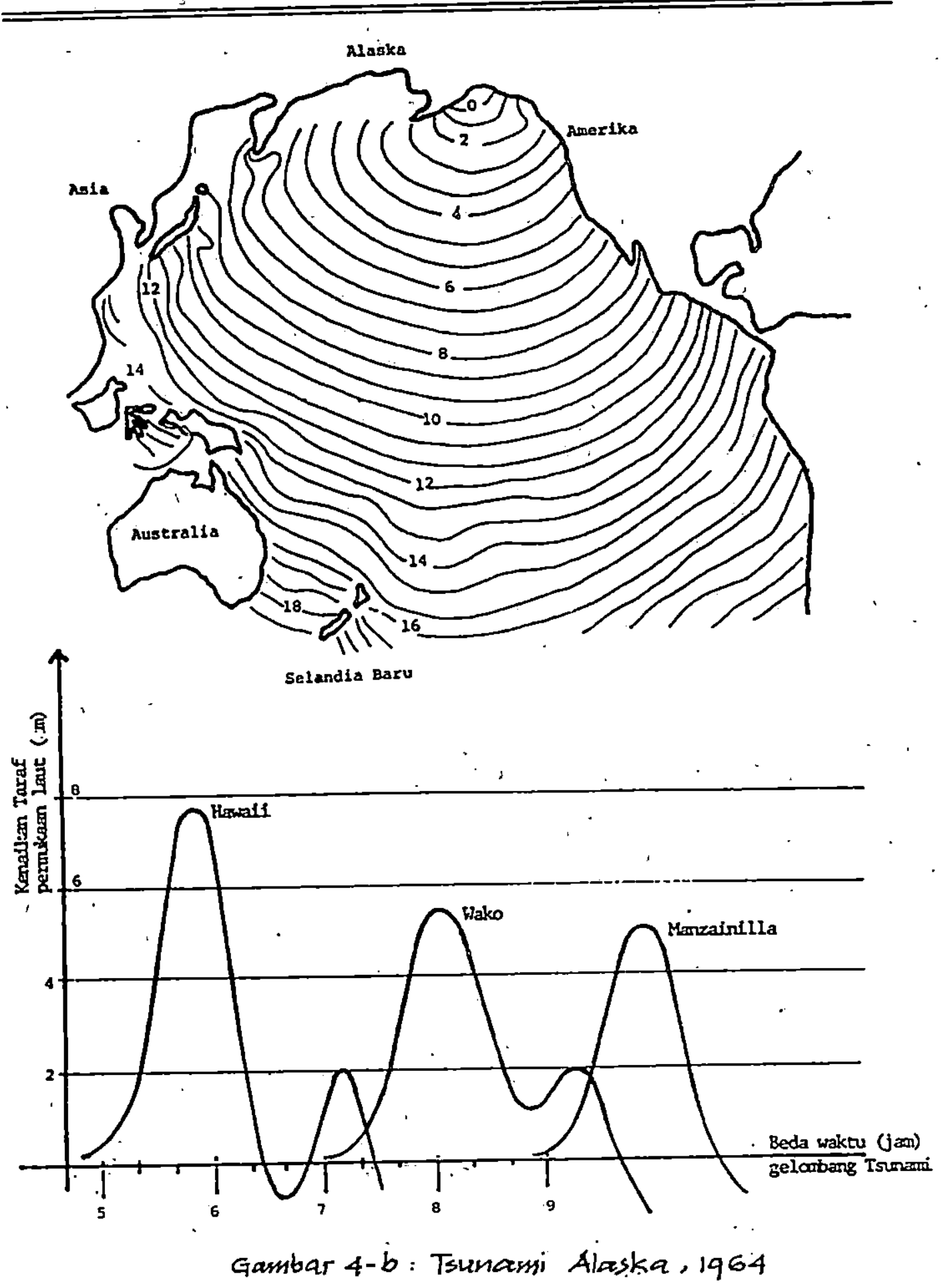

15 


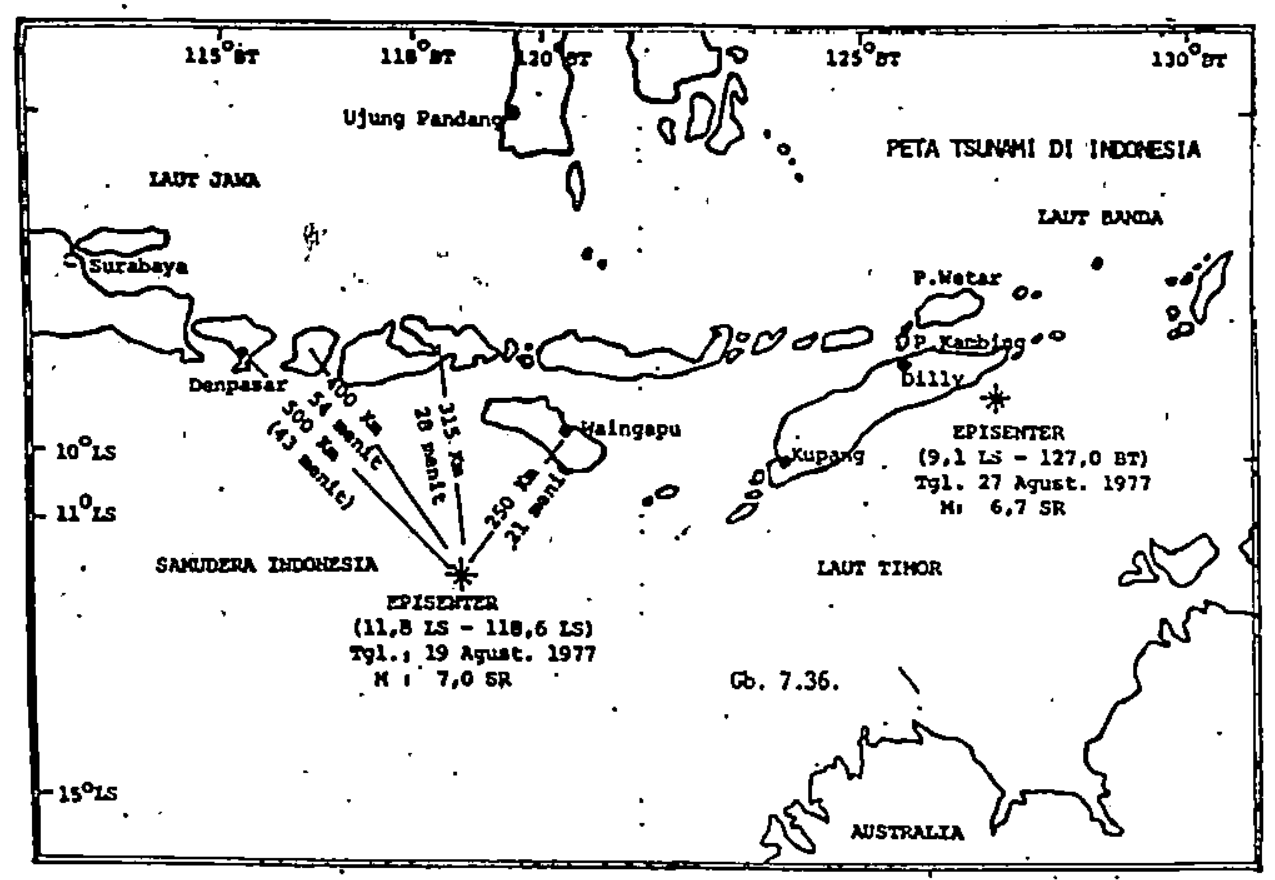

Gambor 2-b : Peta Tsunassi NTT

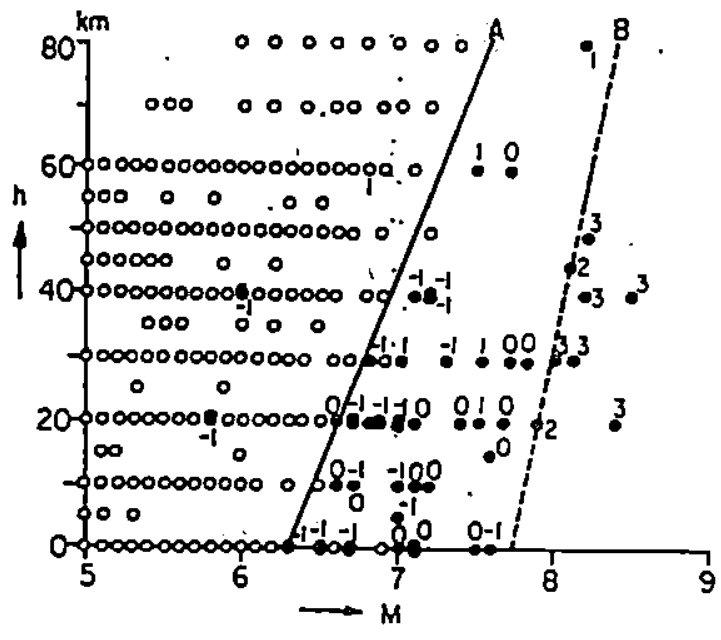

- Eorthquake not occompanied by isunomis.

- Eorthquake óccomponied by isunomis.

The numerol outside of the circle is the isunami mognitude.

Gambar 5 : Hubungan antara magnitude, focal depth, dan tsunami 

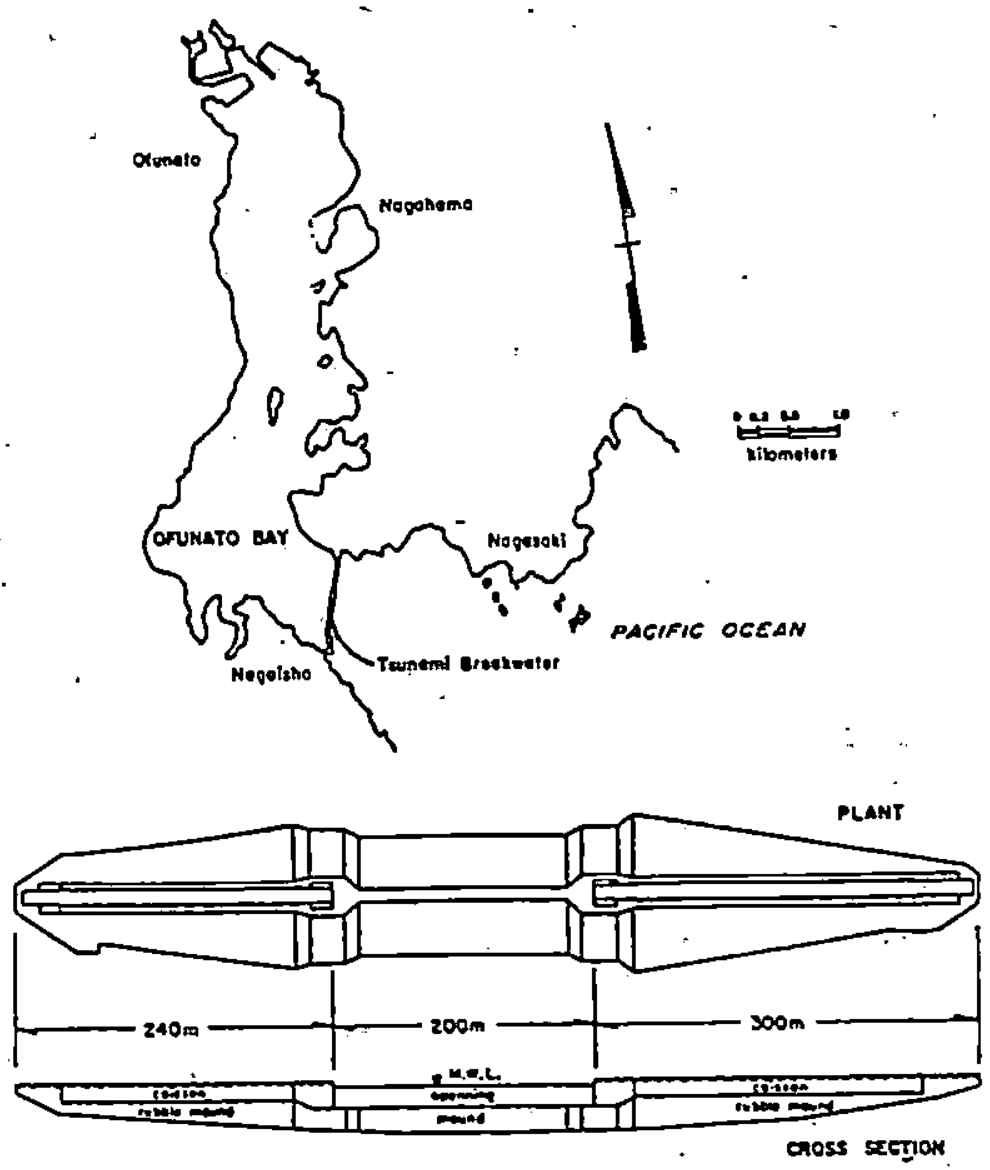

(a) Struktur breakwater

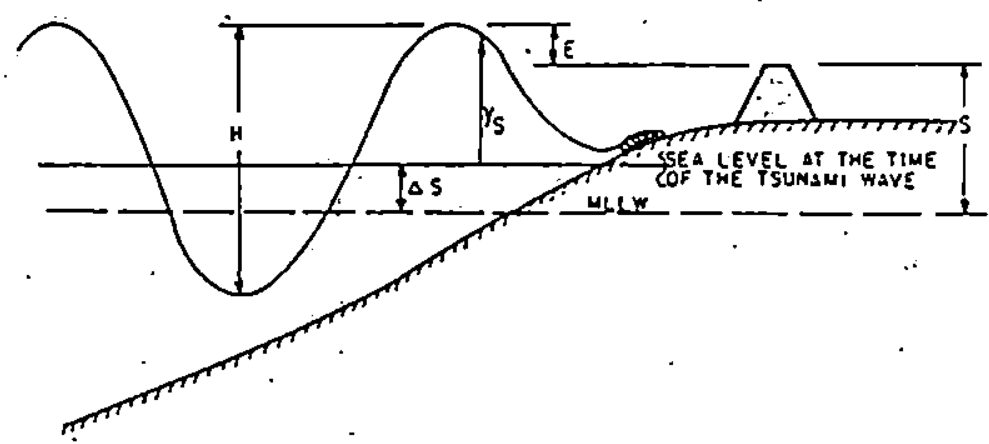

(b) Struktur overtopping seawall

Gambar 6 : Breakwater dan orertopping seanall 
$\infty$
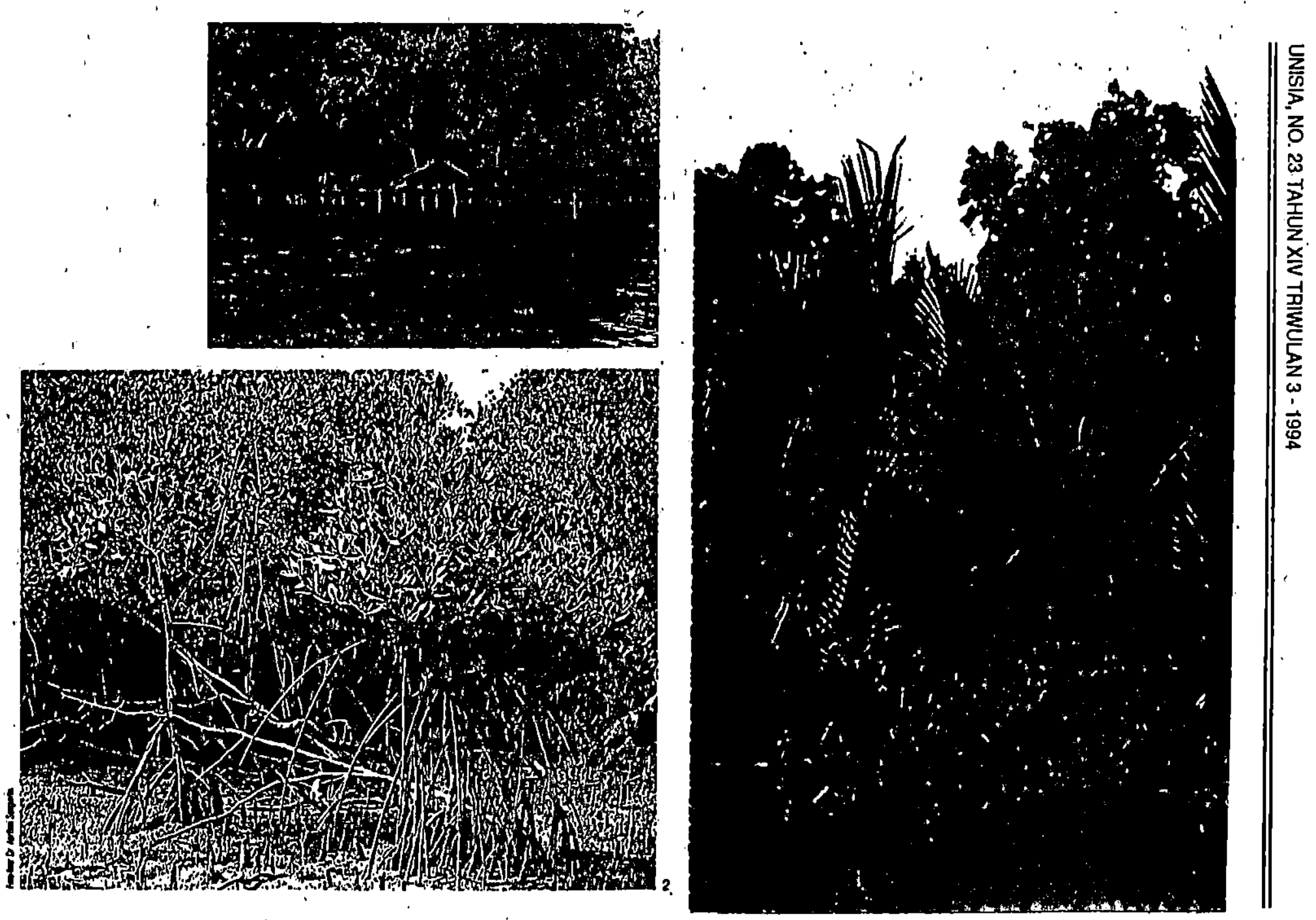


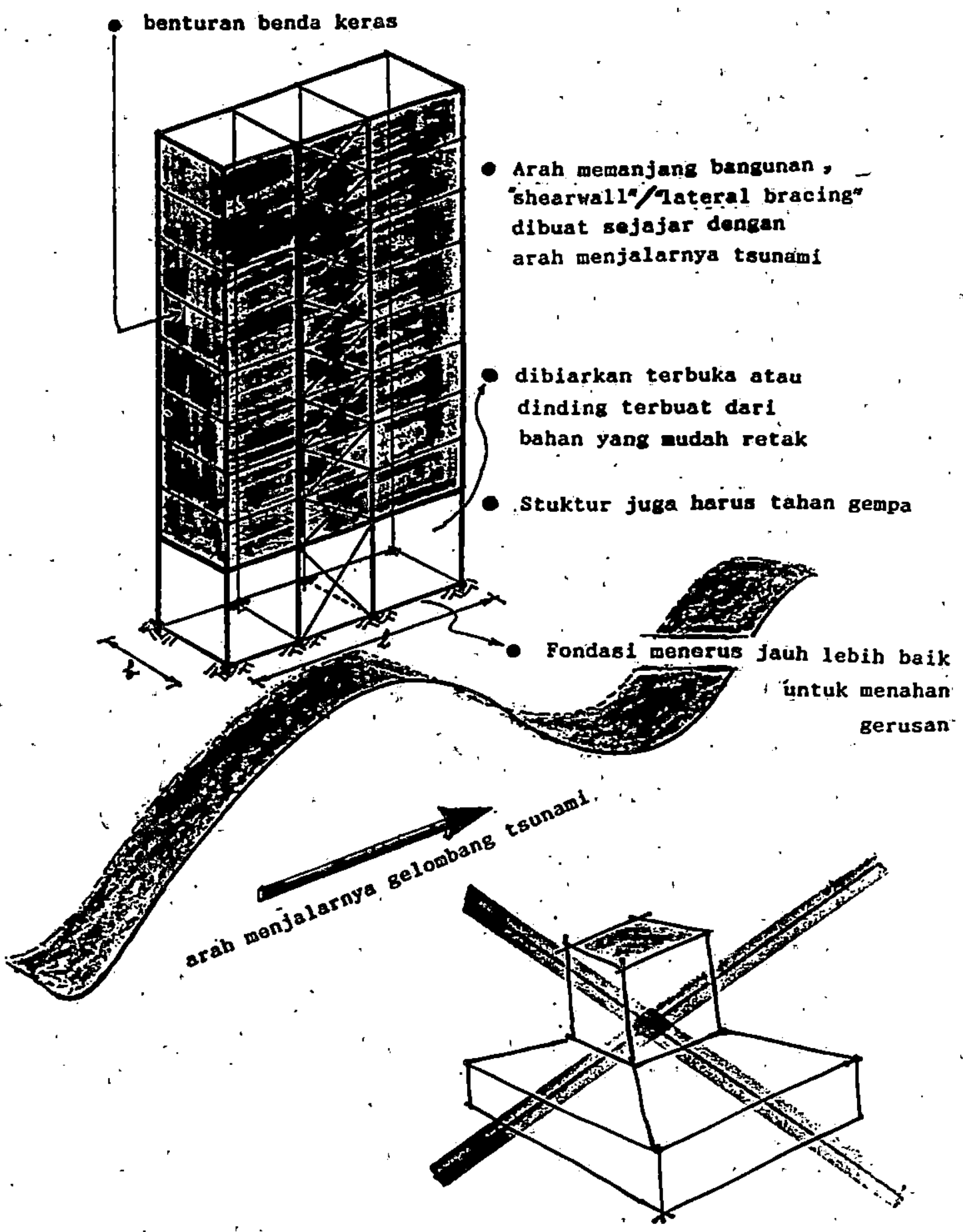

Gambar 8 : Struktur tahan tsunami 